\title{
Generating and using community intelligence: the case of neighbourhood policing
}

\author{
Karen Bullock \\ Department of Sociology, University of Surrey, Guildford, Surrey, GU2 7HQ. \\ Tel: +44(0) 1483 686979; email: k.bullock@surrey.ac.uk
}

\begin{abstract}
This paper examines the role that community generated information plays in 'neighbourhood policing' - a key component of the UK police reform agenda. The neighbourhood policing agenda is concerned with the delivery of a consistent presence of dedicated neighbourhood teams which should be visible and accessible to the community. However, it also calls for the generation of community intelligence which should be used for local problem-solving and should be incorporated into National Intelligence Model (NIM) tasking. At the time of writing the principle of incorporating information generated from the public into policing intelligence and priority setting thus has strong resonance, at least at the level of rhetoric of policy and practice. It is contended that difficult questions are posed in thinking through what it means to consult with the 'public', the nature of community generated information and how it is translated into operational decisions and resource deployment. This paper explores the conceptual foundations of neighbourhood policing - which are found in reassurance policing, problem-oriented policing and the National Intelligence Model. It then examines the current mechanisms for generating community information, prioritising problems, and delivering responses as they are applied in neighbourhood policing. It finishes with a critical discussion of the concept and practice of generating and using community information for setting local policing priorities.
\end{abstract}

\section{INTRODUCTION}

The principle of incorporating information generated from members of the public into police intelligence processes and priority setting has strong resonance at the time of writing. This is especially evident in 'neighbourhood policing' which has constituted a significant element of the UK government's police reform agenda. The neighbourhood policing agenda is concerned with the delivery of visible and accessible teams of police officers who are dedicated to particular geographical neighbourhoods. There has been a great deal of local emphasis on the provision of these teams and considerable resources expended (HMIC, 2008; Policing Green Paper, 2008). The neighbourhood policing agenda has wider concerns however - at least in principle - and is additionally concerned with (1) intelligence-led identification of community concerns about crime; and (2) joint action and problem-solving with the community and other partners to tackle them. With its focus on generating information from the community and using it in local problem-solving — along with a wider call to incorporate it into National Intelligence Model (NIM) tasking - the remit of neighbourhood policing should be about much more than the provision of dedicated neighbourhood teams.

This paper examines the concept and application of 'community intelligence' as it applies in the neighbourhood policing agenda. 'Intelligence' in the policing context has been defined as the 'systematic and purposeful acquisition, sorting, 
retrieval, analysis, interpretation and protection of information' (Sheptycki, 2003). Intelligence is the product of a process though which information is collected, corroborated, refined and ultimately made usable for operational purposes (Ratcliffe, 2008). As Ratcliffe (p. 95) put it, 'crime intelligence [therefore] moves beyond knowledge into the realm of action'. Therefore there is a distinction to be made here between 'information' generated from the community and 'community intelligence'. Reflecting Sheptycki, Innes and Roberts (2008, p. 250) define community intelligence as 'information that when analysed provides insight into the risks posed by and to a particular group of people sharing some facet of common identity. In effect community intelligence is the information developed by the police in order to establish the basis of their reassurance interventions.' Similarly Association of Chief Police Officers [ACPO]/Centrex (2006, p. 25) note, 'community intelligence is local information which, when assessed, provides intelligence on issues that affect neighbourhoods and informs both strategic and operational perspectives in the policing of local communities'. Thus community intelligence is generated from information derived from interaction between the police service and members of the public. It is easy to see how this could be exceedingly wide ranging, encompassing, for example, informal contacts, letters of complaint, views expressed at meetings along with more systematically generated sources of information, such as residents surveys. However, the intelligence process is about more than just the generation of the information - it is additionally about how it is refined and made useable.

The paper first examines the conceptual foundations of neighbourhood policing - which can be found in reassurance policing, problem-solving and the National Intelligence Model (NIM). There are overlaps between these approaches in particular that they all explicitly represent a shift from a reactive focus of policing to a proactive one. However, there are differences in their origins, scope and in the role that members of the public should play in problem identification, priority setting and the development of responses. The differences between the conceptual models are teased out, as are differences between these models and the approach officially adopted by neighbourhood policing. The aim of doing so is not to provide a critique of the models but to describe how they have informed neighbourhood policing. (For a critical account of their conceptual basis see Loader, 2006; and for application in practice see Bullock, Erol, \& Tilley, 2006; Gilling, 1996; John \& Maguire, 2004a, 2004b; Read \& Tilley, 2000). The paper then turns to an examination of the current mechanisms for generating community information and translating it into actionable intelligence, prioritising problems, and delivering responses as they are applied in neighbourhood policing. In doing so it draws on empirical studies which have examined the delivery of neighbourhood policing in practice. It finishes with a critical discussion of the concept and practice of generating and using community information for setting local policing priorities and identifies potential implications for neighbourhood policing.

\section{THE CONCEPTUAL BASIS OF NEIGHBOURHOOD POLICING Signal crime and reassurance policing}

Neighbourhood policing has developed from the concept of 'reassurance policing'. Reassurance policing in turn is rooted in observations that members of the public display significant concerns about crime and disorder even where crime rates are low and/or falling (Fielding \& Innes, 2002). It is informed by the 'signal crime perspective' which proposes that certain incidents (along with the presence of social and physical disorder) influence how people (individually and collectively) perceive 
their environment and level of security (Innes \& Fielding, 2002; Innes, 2004, 2005). Police (or other agency) failure to identify and tackle these events raises public concern about crime and disorder.

'Problems', for the purpose of reassurance policing, are defined in terms of 'signals' which impact on the public's perceptions of safety within a locality. The process of identifying problems is similar to the analysis stages of problem-solving (discussed further below) but focuses specifically on systematically locating (and then tackling) these signals. This is achieved through eliciting the knowledge of 'key informers' who have in-depth knowledge about problems in particular locations. A small number of individuals may thus be selected for their detailed knowledge of an area rather than wider sections of the community consulted. It follows that by tackling these concerns (in conjunction with partner agencies), perceptions of crime and safety can be improved.

These ideas were tested in what was known as the National Reassurance Policing Programme (NRPP). The NRPP was, in effect, an experiment with these ideas in 16 sites in England and Wales. Drawing on the signal crime perspective and on broader models of community policing activities a range of tactics were tested. This included targeted problem-solving involving the identification of problems which mattered to local people and community involvement in prioritising problems for action along with the presence of visible and accessible policing teams. A Home Office evaluation showed that overall the programme had a positive impact on crime, perceptions of crime and anti-social behaviour, feelings of safety and public confidence in the police (Tuffin, Morris, \& Poole, 2006). These results have been widely cited in support of the roll-out of neighbourhood policing.

Even though the origins of neighbourhood policing can be found in reassurance policing, the remit has shifted somewhat as neighbourhood policing has developed (Innes, 2005). Most notably, the principle of systematically tackling signal crimes and disorders has been removed. As will be seen, practice for facilitating community engagement and generating information from members of the public has been left to the discretion of local areas (the stated aim being so that practice can be tailored to local preferences). Whilst the role played by reassurance policing is often acknowledged in official documentation on neighbourhood policing, the discourse and practice has become much wider.

\section{Problem-oriented policing, problem-solving and neighbourhood policing}

The principle of problem-solving has derived from the process described by Goldstein (1979, 1990). (The terms problem-oriented and problem-solving tend to be used interchangeably and are so used in this paper.) Problem-oriented policing is concerned with identifying and homing in on patterns of recurring incidents that are open to intervention by police or other agencies. Goldstein (1990) described problems as clusters of similar, related or recurring problems that represent a substantive community concern and which constitute police business. Problems could be identified in different ways including through routine analysis of police calls for service data or analysis of information from other parts of the police organisation or other agencies, but once a patterned problem has been identified, systematic information about that problem should be gathered in order to describe it in detail. The point of analysis is to determine the nature of the problem and so target responses on an aspect of the problem which is amenable to intervention. Goldstein (1990) stressed that the responses need not be police responses and instead should draw in 
resources from other agencies, as appropriate. Lastly, new responses should be rigorously assessed.

In stressing the role of problem-solving, neighbourhood policing draws heavily on principles and techniques of problem-oriented policing. There are differences between the role of the community in the model described by Goldstein (1990) and that called for in neighbourhood policing, however.

1. Conceptual foundations Reflecting its roots in community policing styles, neighbourhood policing specifically aims to improve relations between the police and the community. As such neighbourhood policing is (in part) a solution to aproblem: the problem of a poor relationship between the public and the police. This contrasts with the problem-oriented approach which is concerned with the identification of problems that cause harm to a community, rather than the police relationship with the community per se (Tilley, 2003).

2. Community role in problem-identification and prioritisation The starting point of neighbourhood policing is the identification and prioritisation of problems which local people consider to be harmful. For Goldstein (1990) the views of the community should not be the only basis on which problems are prioritised.

3. Community role in response development and intervention Neighbourhood policing stresses joint action with communities and partners to solve problems. For problem-oriented policing community involvement in addressing a crime problem is not given.

4. Community role in assessment of interventions Again reflecting its roots, neighbourhood policing calls for an assessment of the impact that an intervention has on the community's view of a problem. For Goldstein (1990), evaluation of new interventions is essential but need not explicitly call on community views. More broadly problem-oriented policing makes much more of the need for systematic evaluation of outcomes than the rhetoric of neighbourhood policing does.

\section{Neighbourhood policing and the National Intelligence Model (NIM)}

NIM has been an important development in UK policing - quite apart from the development of the neighbourhood policing agenda and problem-solving. NIM is defined as 'an information-based deployment system and a cornerstone for the management of law enforcement operations in England and Wales' and it seeks to 'professionalise' and 'improve' intelligence work (ACPO/Centrex, 2005). NIM can make use (in principle) of wide-ranging data sources in understanding crime problems which should be developed into standard intelligence 'products' (see ACPO/Centrex for a discussion of the NIM intelligence products). Information can be obtained from a very wide range of sources - for example from proactive activity, the use of surveillance, CCTV and Automatic Number Plate Recognition (ANPR) systems, informants, command and control systems, crime recording, criminal investigations, fixed penalty and other traffic enforcement measures, firearms licensing, patrol, stop and search, neighbourhood watch and other community information (ACPO/Centrex). These sources of information are clearly much wider than those generally used for problem-solving or reassurance policing. In this context intelligence products should drive either 'strategic' or 'tactical' 'tasking and coordination' meetings where priorities are identified and decisions made about the deployment of resources and 
operational tactics. Unlike problem-solving and reassurance policing, NIM was designed with an explicit standardised structure to facilitate the application of information in decision-making at strategic and tactical levels.

NIM stresses the need to move from reactive to proactive policing and the use of wide-ranging data sources to shape decision-making. In doing so there are similarities with reassurance policing and problem-oriented policing. Certainly, there are similarities with problem-oriented policing. Both are concerned with reforming the business of the police service, both focus on the key role that the systematic use of information should play in policing and both are concerned with reducing crime (Tilley, 2003). Maguire and John (2006) also suggest that NIM — with its focus on analysis and planning interventions on the basis of that analysis - marries relatively well with the problem-solving model. But there are differences too. Problem-oriented policing calls for a focus on long-term systematic analysis; is more likely to look at non-crime (as well as crime) problems; and less likely to depend on police activity as the strategy for tackling problems (Tilley). It has, however, been argued that NIM does not sit so well with the reassurance basis of neighbourhood policing which, with its focus on issues defined by members of the public, could be viewed as less 'objective' and more 'popularist' (Maguire \& John, 2006). It would certainly seem that NIM aims to draw in wide sources of data and seeks to identify problems more widely than those concerns identified by members of the public.

A debate about the compatibility of the conceptual models aside, integration within NIM has been viewed as central to the operation of neighbourhood policing at least in official documentation. On the one hand, neighbourhood policing should be driven by information that has been rigorously analysed, and also through standardised tasking and co-ordination groups. On the other hand, information generated by the neighbourhood policing processes regarding public concerns about local crime problems should be conceived as 'intelligence issues'. That is to say, information generated from members of the public should be assessed and profiled and provide a basis for strategic and tactical decision-making more widely. So, in theory at least, neighbourhood policing should operate through NIM tasking and NIM tasking should include a consideration of issues that are of most concern to the community.

\section{SETTING THE NEIGHBOURHOOD POLICING AGENDA: THE ROLE OF COMMUNITY INTELLIGENCE IN PRACTICE}

\section{Generating information}

An intelligence process is reliant on the generation of information about crime problems. It has already been noted that information gleaned from the community could be conceived widely, however. In practice, the focus of neighbourhood policing has been on generating information about local crime problems and community priorities through 'consultation' (HMIC, 2008). In turn this information should be used in local problem-solving structures and further incorporated into local intelligence systems and evaluated to inform decision-making within NIM (ACPO/Centrex 2006). Consulting with communities regarding crime problems is hardly new within policing. Focus groups, citizens' panels and surveys have all been used by the police service (and partners) to generate information about crime problems and local preferences for tackling them. Historically, perhaps the most common means of consulting with the public has been through police/community meetings. Recommended in the Scarman Report (1981) as a means of improving the relationship between the police service and the public, community consultative groups 
are widely established in England and Wales. Public meetings of this sort have the advantages of being relatively cheap and quickly organised, but on the other hand they are hardly representative of the community and may become dominated by opinionated participants (Forrest, Myhill, \& Tilley, 2005).

Neighbourhood policing guidance does not set out how the police service should 'consult' with communities and so generate information. The idea is to allow local flexibility depending on what local people want. Officially, neighbourhood policing teams should develop an engagement strategy to facilitate the consultation of a wide range of perspectives and should specifically address the needs of 'hard-toreach/hear' (eg, young people, transient groups) and minority groups. However, neighbourhood policing documentation is very clear that forms of consultation should go beyond the traditional meeting style (and presumably the associated problems) noted above.

How then does the police service consult with members of the public in practice? An increase in the reported use of forms of community consultation techniques which go beyond traditional police/community meetings has been identified. For example, the use of street briefings and resident surveys, along with the development of neighbourhood watch (HMIC, 2008; Quinton \& Morris, 2008). HMIC further drew attention to the widespread adoption of 'PACT' (Police and Communities Together) which comprises meetings in which members of the public (at least those who turn up and participate) inform the neighbourhood policing team about the nature of problems in a locality. Following this discussion the top community priorities are decided, the neighbourhood policing team commits to tackling these and reports back to the next meeting on progress. The development of 'key individuals networks' (KIN) - a network of local people who are viewed to have particular knowledge of an area because they live, work or otherwise regularly pass through which provides information about problems locally - was also reported. HMIC note that these mechanisms are 'effective' in extracting community views about crime problems and priorities and suggest that each form of consultation they observed had 'merit'. However, no information is provided about which of these formats are most commonly used, the numbers of members of the public who participate, or the quality of these mechanisms.

Despite the increase in the adoption of more innovative consultative techniques reported by the Home Office and HMIC, there are problems in their operation. Firstly, the format and quality of these meetings varies widely between areas (Casey, 2008). Secondly, despite the stated requirement for police services to identify how local people wish to be consulted, there is evidence of only 'some good practice' in this area (HMIC, 2008). Thirdly, mapping engagement 'gaps' (mapping the postcodes of those members of the community who attend consultation to identify who is and who is not represented) is generally 'in need of development' (HMIC). Lastly, HMIC noted that neighbourhood boundaries were seldom identified, agreed and reviewed with partners and communities. In turn, this meant that forms of consultation, engagement and communication did not necessarily match the needs of communities.

\section{Identifying priorities and developing responses}

The aim of neighbourhood policing is, of course, not just to generate information regarding crime problems but to use it to identify priorities and subsequently to develop responses. As has been seen, local problem-solving structures and NIM are the primary mechanisms for doing so but certain issues are evident in their operation 
Firstly, the delivery of problem-solving principles in the neighbourhood policing context has not been straightforward. In their evaluation of the roll-out of neighbourhood policing, Quinton and Morris (2008, p. 24) argued that 'progress was evident' in terms of the provision of systems to support local level problem-solving but that they could not assess the extent or quality of problem-solving activity on the ground. They noted that police service basic command units had 'basic systems' in place such as training ( 80 per cent) and analytical support ( 77 per cent). However, 'advanced systems' were less common, for example, training for partner agencies (46 per cent), training for local people (46 per cent), carrying out appraisals of neighbourhood problem-solving activity (42 per cent), or recording all problemsolving plans (53 per cent). HMIC (2008, p. 6) identified '... pockets of good practice for joint problem-solving within forces rather than consistency' and further noted that '.. the mainstreaming of processes - in understanding joint problem solving and in the systems - is not yet embedded'. Indeed, commentators have noted that despite the seemingly 'common sense' and 'simple' processes of problem-solving, delivery on the ground has been very challenging (see for example, Read \& Tilley, 2000; Bullock et al., 2006). Problems have been technical (eg, related to analytic capacity), organisational (eg, training staff and developing skills) and cultural (eg, resistance amongst officers to a change in direction of the police service).

Secondly, practice in respect to processing community information via NIM is problematic. Forrest et al. (2005, p. 10) noted that, 'community intelligence can and is - being [sic] used within the framework of the National Intelligence Model, with attempts to feed community intelligence into the tasking process'. However, community generated information appears not to have been integrated into the national intelligence model tasking process in a straightforward manner across police services. HMIC (2008) identified a range of issues and called for improvements to the processes through which community information is used. They noted that the concept of 'community intelligence' is not universally understood within the police service and that the process for the capture, analysis and evaluation of community intelligence is not as well developed as the systems for criminal intelligence are. They further called for partner agencies to provide more information and to be encouraged to assist in the development of tactical solutions and for police services to review their intelligence requirements and systems to ensure that they are 'fit for purpose'.

Thirdly, rightly or wrongly, the premise of neighbourhood policing is that priorities for the teams are determined on the basis of public priorities. There is evidence to suggest that this is not always the case. Quinton and Morris (2008, p. 23) identified a 'large and significant increase in the proportion of BCUs that stated that neighbourhood priorities were mainly set by local people (rather than by the police or partner agencies)'. However, the evidence they present shows that half of the areas were not setting priorities on the basis of those set out by local people. Their analysis compared the problems that had been identified as neighbourhood priorities in a sixmonth period with those problems which had actually been targeted by neighbourhood problem-solving activity. They identified variation and concluded 'that there were relatively large disparities can be seen as an indication that operational policing was not completely responsive to the needs of local people and that the processes of aligning frontline activity to local concerns were not welldeveloped at this early stage of the three-year programme' (Quinton and Morris, p. 24)

\section{Community involvement in developing and delivering responses}


One aim of neighbourhood policing is, of course, to use information generated from the community to generate responses to crime problems and subsequently involve the community in the delivery of those responses. It is easy to imagine the many ways that members of the public may get involved. For example, neighbourhood watch, getting involved with restorative justice, running diversion activities for young people or joining the special (volunteer) police service. Neither Quinton and Morris (2008) nor HMIC (2008) say much about the nature of community involvement in the development and delivery of responses for neighbourhood policing. In discussing neighbourhood policing directly with members of the public, however, Casey (2008) noted that few knew little about it beyond the introduction of officers. She suggests that this provides an insight into what is needed for the next stage of neighbourhood policing '...developing greater public familiarity and securing the public's active participation' (Casey, p. 25).

\section{Community involvement in assessment}

Involving the community in assessing the impact of neighbourhood policing has also been considered important - quite clearly the degree to which local people feel that a problem has been removed or its impact reduced is an important measure of success in this context. Forrest et al. (2005) additionally pointed to how it may be useful to capture the views of the public at the various stages of the problem-solving process in order to maintain and develop community engagement in future endeavours. The evaluation of problem-solving projects has generally been limited (Bullock et al., 2006; Scott, 2000). However, where there has been evaluation, the community has not usually been involved (Forrest et al.). HMIC (2008) pointed to the importance of evaluation and review along with providing feedback to the community to build trust and confidence and further knowledge about what is effective in tackling problems. However, HMIC identified problems regarding the community involvement in evaluation and in providing feedback on interventions and responses delivered and a need for the 'development of coherent problem solving evaluation and the dissemination of good practice within the force and to partners' and 'corporate processes to ensure that communities receive timely updates and feedback' (HMIC, p. 36).

\section{DISCUSSION}

There has been significant investment in and high level support for neighbourhood policing as it has been rolled out throughout England and Wales. At the time of writing most focus appears to have been on the delivery of dedicated teams of officers. Neighbourhood policing should be more than this, however. The operation of neighbourhood policing in respect to the generation of community information, the role that it is playing in setting local priorities along with the arrangements for its capture and analysis within NIM is not straightforward. This section summarises issues and some implications.

Questions are raised regarding the nature of the information generated from communities in this context. The rhetoric of neighbourhood policing focuses on generating information about local priorities via 'consultation' through local problemsolving structures which, in turn, use this information to prioritise problems and develop solutions. PACT and KIN seem to be central to current practice. The limitations of police consultation with the public have been well demonstrated. Especially salient here is the problem that those who participate in consultation tend not to be representative of a community on the whole and consultation exercises 
mostly tap into the views of self-selected consultees. In principle PACT and KIN certainly seem to represent more than traditional police/community structures. They offer a mechanism to focus local problem-solving activities and formally use the product of consultation to generate action. However, ultimately the operation of PACT (like traditional public meetings) is highly reliant on who attends. KIN captures the views of small numbers of individuals who may (but may not) have a view which is shared widely by others. This clearly has implications for the nature of information which is gathered through neighbourhood policing processes. All sources of crime data have limitations of course. Community information about crime problems is likely to be limited in scope in terms of coverage of crime types, may be highly parochial in focus and often turns out to be wrong (Tilley, 2008).

If the information about local crime problems being generated is limited, then it follows that there are implications for subsequent understanding of problems and setting local priorities. In particular, there is a risk that neighbourhood policing activities become focused around the views and preferences of the self-selected consultees. Of course, the neighbourhood policing agenda makes reference to this and calls for the use of multiple sources of information in problem definition and analysis so as to go beyond community perspectives of crime problems. Indeed, in explaining the results of the evaluation of the NRPP, Tuffin et al. (2006) actually point very specifically to the role of a very detailed specification of problems identifying two (if not three) of the 'crime triangle' (cf Cohen \& Felson, 1979) points (eg, a detailed understanding of the offender/s, location or victim/s), and use of multiple sources of information to specify the nature of the problem. Practice seems to be a long way from this (HMIC, 2008; Quinton \& Morris, 2008).

Incorporating the results of consultation into NIM coordinating and tasking offers a way of developing and understanding crime problems that goes further than the expressed perspectives of self-selected consultees and hence the points noted above. However, at the time of writing NIM structures seem to exist somewhat separately and are disconnected from the local problem-solving structures. There are clearly operational difficulties here related to (a) practitioner understanding of community intelligence and (b) the arrangements for the capture or analysis of information generated from members of the public. This may partly reflect the complexity of systematically capturing this information, evaluating it and the difficulties in drawing together very disparate types of information. Indeed, so far the focus of NIM has been on police-generated information and police-identified problems (John \& Maguire, 2004a, 2004b). As such, systems may not be geared up to capture, bring together and analyse different types of information and there may also be resistance to developing priorities on the basis of the views of non-police personnel. At the time of writing it seems that it may be the case that 'information' generated from members of the public is just that. Bearing in mind the definitions noted at the beginning of this paper, whilst information is clearly being generated from members of the public through consultation exercises, the extent to which it is being translated into actionable 'intelligence' is less clear.

In conclusion it is clear that the processes of generating community intelligence are far from straightforward. If the neighbourhood policing agenda is to be successful in moving beyond the delivery of visible policing teams to a process which facilitates understanding of crime problems and hence the development of strategies for tackling crime, then attention needs to be paid to certain areas. There is a need to consider the nature of the information generated from local consultation exercises and especially 
the issue of who is (and who is not) represented in local consultation. Along with this, there needs to be raised the organisational capacity to rigorously analyse multiple sources of data (including that generated from members of the public), in order to systematically identify and prioritise problems and develop responses to them. Without this, there would seem to be a risk that the police service, through neighbourhood policing, will find it has committed itself to a highly resourceintensive consultation exercise which will do little to understand and diminish crime problems and, at worst, it may force the police service to focus attention on highly parochial concerns.

\section{REFERENCES}

ACPO/Centrex. (2005). Guidance on the National Intelligence Model. Wyboston: Centrex.

ACPO/Centrex. (2006). Practice Advice on Professionalizing the Business of Neighbourhood Policing. Wyboston: Centrex.

Bullock, K., Erol, R., \& Tilley, N. (2006). Problem-oriented Policing and Partnership. Cullompton: Willan Publishing.

Casey, L. (2008). Engaging Communities in Fighting Crime. London: Cabinet Office. Cohen, L., \& Felson, M. (1979). Social Change and Crime Rate Trends: A Routine Activity Approach. American Sociological Review, 44, 588-605.

Fielding, N., \& Innes, M. (2002). From Community to Communicative Policing: Signal Crime and the Problem of Public Reassurance. Sociological Research Online, $7(2)$.

Forrest, S., Myhill, A., \& Tilley, N. (2005). Practical Lessons for Involving the Community in Crime and Disorder Problem-Solving (Development and Practice Report 43). London: Home Office.

Gilling, D. (1996). Problems with the Problem-oriented Approach. In R. Clarke (Series Ed.) \& R. Homel (Vol.Ed.), Crime Prevention Studies: Vol. 5. The Politics and Practice of Situational Crime Prevention (pp. 9-24). Monsey, NY: Criminal Justice Press.

Goldstein, H. (1979, April). Improving Policing: A Problem-Oriented Approach. Crime and Delinquency, 236-258.

Goldstein, H. (1990). Problem-Oriented Policing. New York: McGraw-Hill. Her Majesty's Inspectorate of Constabulary. (2008). Her Majesty's Inspectorate of Constabulary - serving neighbourhoods and individuals (A thematic report on Neighbourhood Policing and Developing Citizen Focus Policing). London: author. Innes, M. (2004). Signal Crime and Signal Disorders: Notes on Deviance as Communicative Action. British Journal of Sociology, 55(3), 335-355.

Innes, M. (2005). Why 'Soft' Policing is Hard: On the Curious Development of Reassurance Policing, How it became Neighbourhood Policing and What This Signifies about the Politics of Police Reform. Journal of Community and Applied Social Psychology, 15, 156-169.

Innes, M., \& Roberts, C. (2008). Reassurance Policing. Community Intelligence and the Co-Production of Neighbourhood Order. In T. Williamson (Ed.), Knowledgebased Policing: Current Conceptions and Future Directions. Chichester, West Sussex: Wiley and Sons.

John, T., \& Maguire, M. (2003). Rolling out the National Intelligence Model: Key Challenges. In K. Bullock \& N. Tilley (Eds.), Crime Reduction and Problem Oriented Policing. Cullompton: Willan Publishing. 
John, T., \& Maguire, M., with the assistance of Quinn, A., Rix, A., \& Raybould, S. (2004a). The National Intelligence Model: Early Implementation in Three Police Force Areas (Working Paper Series Paper 50). Cardiff: University of Cardiff.

John, T., \& Maguire, M. (2004b). The National Intelligence Model: Key Lessons from Early Research (Online Research Paper 30/04). London: Home Office.

John, T., \& Maguire, M. (2006). Intelligence-led Policing and Community

Engagement: Competing Priorities and the Role of the National Intelligence Model in the UK. Policing and Society, 16(1), 67-85.

Loader, I. (2006). Policing, Recognition, and Belonging. Annals of the American Academy of Political and Social Science, 605, 201-221.

Quinton, P., \& Morris, J. (2008). Neighbourhood policing: the impact of piloting and early national implementation (Home Office Online Report 01/08). London: Home Office.

Ratcliffe, J. (2008). Intelligence-led Policing. Cullompton: Willan Publishing. Read, T., \& Tilley, N. (2000). Not Rocket Science?: Problem-solving and Crime Reduction (Crime Reduction Research Series Paper 6). London: Home Office. Sheptycki, J. (2003). Review of the Influence of Strategic Intelligence on Organised Crime Practice and Policy. London: Home Office, Policing and Reducing Crime Unit. Tilley, N. (2003). Problem-Oriented Policing, Intelligence Led Policing and the National Intelligence Model. London: University College London.

Tilley, N. (2008). The Development of Community Policing in England: Networks, Knowledge and Neighbourhoods. In T. Williamson (Ed.), Knowledge-based Policing: Current Conceptions and Future Directions. Chichester, West Sussex: Wiley and Sons.

Tuffin, R., Morris, J., \& Poole, A. (2006). An evaluation of the impact of the National Reassurance Policing Programme (Home Office Research Study 296). London: Home Office. 